\title{
A TUTELA PROCESSUAL COLETIVA DO CONSUMIDOR A PARTIR DA ATUAÇÃO CONCERTADA DOS LEGITIMADOS ATIVOS
}

SUMÁRIO: Introdução; 2 A legitimação ativa nas ações coletivas; 3 Aprofundando o debate sobre a atuação qualificada das Associações Representativas na defesa processual coletiva do consumidor; 4 As mazelas da superdependência dos legitimados extraordinários ao pretenso impulso oficial do Judiciário na movimentação do processo; 5 Isenção de custas e bonorários sucumbenciais nas ações coletivas; 6 Possibilidade de inversão do ônus da prova nas demandas coletivas; 7 Litisconsórcio ativo entre o Ministério Público Federal e o Estadual; 8 Conclusão; Referências.

RESUMO: O presente artigo, através do método dedutivo e de pesquisa teórica de natureza bibliográfica, objetiva apresentar as virtudes da legitimação extraordinária para a defesa processual coletiva do consumidor, indicando eventuais obstáculos na ocupação desse relevante espaço político de deliberação qualificada, bem como será apresentado o contexto atual de algumas garantias processuais adjacentes da jurisdição civil coletiva, como a isenção de custas e a inversão do ônus da prova. Como problema, é indagado se a instrumentalização transindividual seria a melhor opção para a correção dos mais diferentes desvios de comportamento dos agentes econômicos do mercado numa sociedade hipervulnerável pela globalização do assédio de consumo, este caracterizado pelos métodos comerciais coercitivos, técnicas predatórias de contratação em massa, bem como pelas armadilhas do ambiente digital. Conclui-se que a instrumentalização coletiva dos interesses do consumidor, pela articulação concertada dos legitimados ativos, exerceria uma força contra majoritária em relação aos detentores dos meios de produção, que seriam compelidos a mudanças substanciais nos padrões de qualidade e segurança dos bens de consumo, algo que a atuação acidental do consumidor pela via individual jamais conseguirá.

PALAVRAS-CHAVE: Direito do consumidor; Tutela transindividual do consumidor; Legitimação extraordinária; Ações coletivas.

\footnotetext{
Doutor em Direito do Consumidor pela Universidade de Salamanca (Espanha). Docente da Graduação e do Programa de Pós-graduação Stricto Sensu da UFPA, Docente da Graduação e Especialização do Cesupa. Docente da Pós-graduação em Direito do Consumidor da UFRGS. Procurador do Estado do Pará e Advogado, Brasil. E-mail: dennis@gavl.com.br
} 


\title{
CONSUMERS` COLLECTIVE LEGAL TUTELAGE DERIVED FROM THE ASSOCIATED PRACTICE OF LEGITIMATED ASSETS
}

\begin{abstract}
The qualities of extraordinary legitimation for consumers' collective legal defense are forwarded by deduction method and bibliographical research. The paper also comprises eventual impairments in the occupation of such important political space for qualified deliberation. Current context of legal warrants in collective civil jurisdiction, such as costs exemption and the inversion of the burden of proof, is also given. It may be investigated whether transindividual instrumentation is the best option to correct the several behavior types of waywardness of the market's economic agents within a highly vulnerable society assailed by global consumption. The latter is characterized by coercive commercial methods, predatory mass contracting techniques and ploys of the digital environment. Results demonstrate that collective instrumentation of consumers' interests would exert, through the joint articulation of legitimated assets, a counter majority force with regard to the holders of production means which would be compelled to substantial changes in quality and safety standards in consumers' goods. The eventual intervention of the individual consumer would never attain such results.
\end{abstract}

KEY WORDS: Consumers' rights; Consumers' transindividual tutelage; Extraordinary legitimation; Collective actions.

\section{LA TUTELA PROCESUAL COLECTIVA DEL CONSUMIDOR A PARTIR DE LA ACTUACIÓN CONCERTADA DE LOS LEGITIMADOS ACTIVOS}

RESUMEN: En el presente artículo, por intermedio del método deductivo y de investigación teórica de naturaleza bibliográfica, tiene por objetivo presentar las virtudes de la legitimación extraordinaria a la defensa procesual colectiva del consumidor, indicando eventuales obstáculos en la ocupación de ese relevante espacio político de deliberación cualificada, así como será presentado el contexto actual de algunas garantías procesuales adyacentes de la jurisdicción civil colectiva, como la dispensa de costos y la inversión del peso de la prueba. Como problema, se indaga si la instrumentalización transindividual sería la mejor opción a la corrección de los más diferentes desvíos de comportamiento de los agentes económicos del mercado en una sociedad súper vulnerable por la globalización del acoso de consumo, este caracterizado por los métodos comerciales coercitivos, técnicas predatorias de contratación en masa, así como por las trampas del ambiente digital. Se concluye que la instrumentalización colectiva de los intereses del consumidor, por intermedio de la articulación concertada de los legitimados activos, ejercería una fuerza contra mayoritaria en relación a los detentores de los medios de producción, que serían compelidos a cambios substanciales en los patrones de calidad y seguridad de los 
bienes de consumo, algo que la actuación accidental del consumidor por la vía individual jamás conseguirá.

PALABRAS CLAVE: Derecho del consumidor; Tutela Transindividual del Consumidor; Legitimación Extraordinaria; Acciones Colectivas.

\section{INTRODUÇÃO}

Com o surgimento da lei 8.078/90 (Código de Defesa do Consumidor - CDC), houve uma opção muita clara do legislador pelo reconhecimento e instrumentalização dos interesses transindividuais, não apenas como nova expressão plural de um direito solidário, mas também porque se previa a impossibilidade gerencial doJudiciário lidar com o crescimento exponencial dos conflitos de consumo, cuja pulverização individual inviabilizaria o próprio reconhecimento jurisdicional satisfatório, levando à banalização da proteção normativa do consumidor. Isso, também, macularia a imagem do Judiciário como última fronteira na proteção do consumidor, enquanto parte economicamente vulnerável na relação de consumo, pois não teria condições operacionais de processar e responder em tempo razoável tantas provocações individuais e crescentes.

Não significa dizer que os direitos individuais subjetivos tenham sido preteridos no âmbito da proteção processual do CDC, mas fica evidente a ênfase dada a um novo modelo de jurisdição civil coletiva, em que os interesses coletivos teriam maior protagonismo, tanto que dos quatro conceitos legais de consumidor, dois ostentam a pecha de transindividuais (consumidor coletividade que haja intervindo nas relações de consumo do art. $2^{\circ}$, parágrafo único e consumidor exposto às práticas abusivas previsto do art. 29), justamente para viabilizar o reconhecimento do consumidor não apenas como sujeito, mas como categoria e, nessa dimensão, precisaria de uma adequada base instrumental, que viabilizasse tantos direitos materiais introduzidos a partir de então.

Ao se optar por um modelo de legitimação extraordinária na lei, garantiuse um rol de atores coletivos com capacidade técnica presumida para propor, acompanhar e executar as demandas coletivas em matéria de consumo numa suposta rede de proteção concertada e sofisticada, para lidar com a proliferação das práticas abusivas e impingir ao segmento empresarial novos compromissos éticos 
voltados para o aprimoramento da qualidade e segurança dos produtos e serviços colocados no mercado.

Entretanto, a superdependência ao impulso oficial do processo no Judiciário, hoje, cobra sua conta, na medida em que grande parte das ações coletivas judicializadas no país não chegam sequer ao trânsito em julgado e não trouxeram grandes resultados práticos porque os legitimados coletivos não demonstraram o necessário esforço de acompanhamento processual, pugnando não apenas pelas tutelas de cognição sumária, mas pelo desfecho definitivo do processo e a satisfação efetiva das pretensões nele discutidas.

O presente artigo, pelo método dedutivo e de pesquisa teórica de natureza bibliográfica, objetiva apresentar as virtudes da legitimação extraordinária para a defesa processual coletiva do consumidor, indicando eventuais obstáculos na ocupação desse relevante espaço político de deliberação qualificada, bem como será apresentado o contexto atual de algumas garantias processuais adjacentes da jurisdição civil coletiva, como a isenção de custas e a inversão do ônus da prova.

Como problema de pesquisa, indaga-se se a instrumentalização transindividual seria a melhor opção para a correção dos mais diferentes desvios de comportamento dos agentes econômicos do mercado numa sociedade hipervulnerável pela globalização do assédio de consumo, este caracterizado pelos métodos comerciais coercitivos, técnicas predatórias de contratação em massa, bem como pelas armadilhas do ambiente digital.

\section{LEGITIMAÇÃO ATIVA NAS AÇÕES COLETIVAS}

A legitimação ativa nas ações coletivas está prevista nos artigos $5^{\circ}$ da lei 7.347/85 e 82 do CDC, que contempla os legitimados oficiais (Ministério Público, Defensoria Pública, Entidades Federativas etc.), bem como fortalece a ideia de solidariedade, quando autoriza, também, a possibilidade das associações representativas da sociedade civil instrumentalizarem a defesa do consumidor em juízo.

A legitimação ativa para a tutela coletiva, por uma opção pluralista do 
legislador ${ }^{02}$, será extraordinária, concorrente, disjuntiva e não exclusiva.

A legitimação será extraordinária, pois não haverá coincidência de sujeitos na relação jurídica material e processual. Embora os legitimados coletivos do artigo 82 possam estar no exercício pleno de uma função institucional, como, por exemplo, o Ministério Público e a Defensoria Pública e sejam verdadeiros sujeitos processuais ativos, o direito material por eles defendido em juízo não lhes pertence. $\mathrm{O}$ interesse será de titularidade de pessoas determinadas ou indeterminadas, mas sempre pertencerá a terceiros que não fazem parte da relação processual, no caso, da coletividade que será substituída. ${ }^{03}$

Para Gidio ${ }^{04}$ a legitimação extraordinária corresponderá a uma espécie anômala de substituição processual secundum eventum litis, em que o substituído seria atingido apenas pela coisa julgada da sentença favorável.

Será concorrente porque todos os legitimados coletivos concorrem em condição de igualdade para a propositura da ação, não havendo privilégios, nem tampouco a ideia de substituto preferencial.

Também será disjuntiva e não exclusiva, pois além de não haver a necessidade de autorização prévia dos demais entes para a propositura da ação por um dos legitimados (caráter disjuntivo), onde cada qual possuirá autonomia para a iniciativa das demandas, o ajuizamento da ação por um dos autores coletivos não excluirá a possibilidade dos demais atuarem, seja por meio de um litisconsórcio ativo, seja de maneira independente, observando-se, naturalmente, as regras de competência concorrente e os limites objetivos e subjetivos de cada lide (caráter não exclusivo).

O rol relativamente extenso de legitimados na defesa coletiva do consumidor busca evitar que a concentração de poder apenas em uns poucos atores possa influenciar negativamente na iniciativa e no acompanhamento das ações, o que pode repercutir num maior nível de frustração quanto aos efeitos da tutela coletiva para o efetivo aprimoramento das relações de consumo e consequente assimilação dos deveres éticos por parte dos agentes econômicos de mercado.

Quanto mais qualificada e concertada a atuação dos legitimados ativos, maiores serão as chances de decisões vantajosas para o consumidor, seja cominando o cumprimento forçado de obrigações legais e contratuais, seja revendo práticas

\footnotetext{
${ }^{02}$ Seguindo as ondas renovatórias no processo evolutivo de acesso à ordem jurídica justa, a saber: $1^{\text {a }}$ ) assistência judiciária; $2^{\mathrm{a}}$ ) construção de modelos de representação jurídica para os interesses metaindividuais, em especial no âmbito ambiental e consumerista; e $3^{\mathrm{a}}$ ) acesso à justiça e instrumentalidade processual.

${ }^{03}$ GIDI, Antônio. A coisa julgada e litispendência em ações coletivas. São Paulo: Saraiva, 1995, p. 44.

${ }^{04}$ GIDI, loc. cit.
} 
abusivas, seja impingindo ao segmento empresarial condenações pecuniárias com forte apelo pedagógico, resultados esses mais tangíveis em demandas coletivas, que nas individuais.

Para Bujosa Vadell ${ }^{05}$, a legitimação ativa nas ações coletivas na Espanha seria guardada as diferenças com o modelo brasileiro.

En definitiva, existiría una legitimación procesal activa, de tipo colectivo amplio, cuando quien interpone la demanda afirma encontrarse en una posición jurídico subjetiva equivalente a la de quien ejercita lo que se ha definido como un interés de grupo en cualquiera de sus modalidades: colectivo, difuso, individual pero de relevancia colectiva ${ }^{06}$, y que puede corresponder tanto a un grupo organizado con capacidad para ser parte, como a un grupo inorgánico debidamente representado, bien por una persona jurídica o mero individuo (o también una pluralidad limitada de individuos), pidiendo el que actúa en el proceso los efectos jurídicos correspondientes a título de hipótesis según el Derecho Material.

Haverá, por conseguinte, uma natural elevação dos níveis de qualidade e segurança dos bens de consumo e constante aprimoramento e diversificação dos canais de atendimento ao consumidor, aproximando-o de suas expectativas originais em observância ao princípio da boa-fé objetiva.

É inegável que o maior legado do CDC, no que diz respeito à legitimação extraordinária para a propositura das ações coletivas, foi o grande estímulo à atuação das associações representativas de defesa do consumidor, conquanto a LACP, em seu artigo $5^{\circ}$, já houvesse contemplado a participação da sociedade civil nesse contexto deliberativo e de acesso político ao Judiciário, foi apenas por meio do CDC que essa possibilidade se tornou efetiva, até porque muitos foram os estímulos estampados nas diretrizes e princípios da Política Nacional das Relações de Consumo.

A legitimação ativa para as ações coletivas está prevista no inciso IV do artigo 82, que dotou a sociedade civil organizada de idêntica legitimidade para a defesa coletiva do consumidor, permitindo-lhe a fruição plena do novo modelo de cidadania participativa proposto pela transição paradigmática, para que não dependesse apenas de garantias metassociais na defesa de seus interesses, ou seja,

${ }^{05}$ BUJOSA VADELL, Lorenzo. La protección jurisdicional de los intereses de grupo. Barcelona: José María Bosh Editor, S.A, 1995, p. 264.

${ }^{06}$ Equivalente, no Brasil, aos interesses individuais homogêneos. 
que não ficasse à mercê da vontade estatal, da iniciativa do Ministério Público ou de outros órgãos oficiais para a defesa dos seus interesses em juízo.

\section{APROFUNDANDO O DEBATE SOBRE A ATUAÇÃO QUALIFICADA DAS ASSOCIAÇÕES REPRESENTATIVAS NA DEFESA PROCESSUAL COLETIVA DO CONSUMIDOR}

Não só órgãos públicos estão legitimados à defesa dos interesses ou direitos difusos, coletivos ou individuais homogêneos. Também as associações e entidades civis de caráter privado foram autorizadas. É a sociedade civil atuando na defesa de seus membros, em juízo ou fora dele, tal como consta da autorização constitucional $\left(\operatorname{art} .5^{\circ}, \mathrm{XXI}\right) .^{07}$

A expressão associação abrange também os sindicatos, as cooperativas e demais entidades de associativismo, de modo a garantir a participação de toda a sociedade civil..$^{08}$

Não há exigência de autorização da assembleia, posto que a defesa dos interesses dos associados deve ser objetivo permanente das associações. ${ }^{09}$

Entretanto, quando o inciso IV fala das associações representativas, estabelece duas condicionantes para que a sociedade civil possa atuar: uma de ordem temporal, pela exigência da pré-constituição pelo prazo de pelo menos um ano; e outra, de ordem formal, relativa à inclusão em meio aos seus estatutos da finalidade específica da defesa do consumidor.

As condicionantes visam, num primeiro momento, tornar seletiva e melhor qualificada a defesa coletiva do consumidor pela sociedade civil, evitando a proliferação de demandas aventureiras intentadas por entidades não profissionais que, por sua falta de experiência processual, poderiam até prejudicar os interesses do consumidor.

Por outro lado, um dos maiores desafios para se alcançar de maneira plena o novo paradigma do conhecimento-emancipação ${ }^{10}$, a saber: a ideia de solidariedade,

\footnotetext{
${ }^{07}$ ALMEIDA, João Batista de. Aspectos controvertidos da ação civil pública: doutrina e jurisprudência. São Paulo: Editora Revista dos Tribunais, 2001, p. 111.

08 ALMEIDA, loc. cit.

09 ALMEIDA, loc. cit.

${ }^{10}$ Cf. SANTOS, Boaventura Sousa. Crítica da Razão Indolente: contra o desperdício da experiência. 2.ed. Porto: Edições Afrontamento, 2002.
} 
é justamente o combate à indolência social, ou seja, a incapacidade da sociedade civil de se articular politicamente e participar de maneira ativa do processo deliberativo para a construção do direito, sendo as condicionantes acima um obstáculo adicional nesse cenário.

A simples mudança de perspectiva de uma subjetividade individual para a coletiva a partir da própria ideia de empatia social envolverá anos de experimentação política, sendo a legitimação extraordinária conferida à sociedade civil nas ações coletivas uma ótima oportunidade para a difusão dessa nova mentalidade, não sendo, portanto, razoável que tal espaço político de deliberação seja restringido por exigências formais.

A partir de uma interpretação teleológica é possível flexibilizar essas exigências, porquanto o próprio $\S 1^{\circ}$ do artigo 82 prevê certas circunstâncias em que seria possível dispensar o requisito da pré-constituição, a saber: "[...] manifesto interesse social, evidenciado pela dimensão, ou características do dano, ou pela relevância do bem jurídico a ser protegido".

A análise do dispositivo supra sugere conceitos abertos que favorecem a amplitude do dispositivo legal, justamente para albergar a legítima ocupação desse relevante espaço político de deliberação pelo Poder Judiciário, estimulando o acesso à justiça e à própria lógica da solidariedade entre estranhos, formando o conceito categórico de consumidor.

Grande indagação reside na possibilidade de se estender os critérios de flexibilização do requisito temporal, por analogia, para o requisito formal da previsão estatutária da defesa do consumidor pela associação autora.

A ideia parece ir ao encontro do modelo de participação cívica proposto pela transição paradigmática, a partir de uma interpretação sistemática e não menos teleológica do $\mathrm{CDC}$, porquanto não se pode admitir que uma mera exigência formal seja suficiente para inibir a articulação social de uma associação civil na defesa de interesses representativos de grupos, ou da própria categoria indivisível de consumidores. Tal possibilidade soa como algo despropositado em meio a tantos outros dispositivos legais que sugerem justamente o contrário, tais como a pluralidade de conceitos legais de consumidor e com enfoque especial naqueles de alcance coletivo, a relativização da coisa julgada, a substituição processual, os novos provimentos jurisdicionais, as tutelas de urgência, os meios dissuasórios para a garantia do cumprimento das decisões judiciais, ou seja, tudo ilustra a nova 
perspectiva instrumentalista do processo para garantir novos canais de acesso à justiça, diferentemente do que se vê com a imposição de condicionantes para a atuação das associações civis.

A simples previsão legal da legitimação extraordinária do inciso IV do artigo 82 para as associações representativas já sinalizava para uma nova vertente de compartilhamento de autoridade político-decisória entre o Estado e a sociedade no âmbito das relações de consumo.

Na mesma toada, a flexibilização do requisito temporal a partir de critérios abertos de interpretação, como na hipótese de manifesto interesse social ou relevância do bem jurídico a ser preservado, cuja subjetividade pode operar sempre em favor de maior amplitude do dispositivo, pois serve para justificar a exceção como regra e, ao mesmo tempo, servir de parâmetro analógico para se buscar idêntica tentativa no caso do requisito formal, muito embora as decisões judiciais sejam raríssimas no enfretamento desta controvérsia.

Ademais, é importante assinalar que a criação de associações independe de qualquer espécie de aprovação oficial, sendo vedada qualquer espécie de interferência estatal em seu funcionamento, ao contrário, impõem-se ao Estado mecanismos para incentivar essa cultura gregária de solidariedade, inclusive como meta específica da Política Nacional das Relações de Consumo, prevista no artigo $4^{\circ}$, II, "b" do CDC.

Para Pedro Lenza ${ }^{11}$,

[...] elas têm autonomia para formular os seus estatutos, sendo que a única forma de dissolver compulsoriamente uma associação já constituída será por meio de decisão judicial transitada em julgado, na hipótese de finalidade ilícita.

A suspensão de suas atividades também se dará por intermédio de decisão judicial, não sendo necessário aguardar o trânsito em julgado, podendo, implementá-la através de provimentos antecipatórios, ou cautelares e as entidades associativas, quando expressamente autorizadas, têm legitimidade para representar seus filiados judicial ou extrajudicialmente, podendo, como substitutas processuais, defender, em nome próprio, o direito alheio de seus associados, além dos interesses transindividuais através das ações coletivas.

\footnotetext{
${ }^{11}$ LENZA, Pedro. Teoria Geral da Acão Civil Pública. São Paulo: Revista dos Tribunais, 2003, p. 188, grifo nosso.
} 
Ademais, a Constituição Federal, quando se refere ao direito de associação, é bastante analítica no artigo $5^{\circ}$, em seus incisos XVII, XVIII, XIX, XX, XXI, dispondo desde a liberdade de associação, passando pela independência delas em relação ao Estado, culminando no inciso XXI com a legitimidade representativa, o qual assevera que "as entidades associativas, quando expressamente autorizadas, têm legitimidade para representar seus filiados judicial ou extrajudicialmente".

Em outras palavras, a norma constitucional não faz qualquer referência a qualquer dos requisitos objetivos que são exigidos pela legislação infraconstitucional (Lei da Ação Civil Pública e o Código de Defesa do Consumidor) para o exercício do direito de ação coletiva pelas associações; ou seja, não há, em tese, necessidade de a associação demonstrar, para "representar" seus filiados em juízo, a regular constituição há mais de um ano, ou mesmo a coincidência das suas razões institucionais com o objeto de uma ação que tenha por base o disposto constitucional. ${ }^{12}$

Negrão arremata ${ }^{13}$ que

Na realidade, o equívoco está em se exigir autorização dos associados para que uma associação possa ingressar com a ação coletiva propriamente dita, o que já não ocorre no caso de simples representação, como disposto no texto constitucional. É que para o caso da ação coletiva que tem por finalidade a defesa de qualquer das modalidades de direitos coletivos "lato sensu", esta exigência, a nosso ver, contraria a própria inspiração do instituto. É certo que o referido parágrafo único do art. $2^{\circ}-\mathrm{A}$ da Lei $9.494 / 97$ está de acordo com as demais medidas adotadas recentemente pelo Poder Executivo e reiteradas pelo legislativo no sentido de reduzir o poder das ações coletivas (principalmente quando o próprio estado é a parte passiva), fracionando a coisa julgada. Tratase de norma dirigida e com finalidade política, calcada em pretensa proteção da coisa pública, mas que, na realidade, apenas desvirtua a grande capacidade que tem (e teria não fosse este tipo de medida legislativa) a ação coletiva de concentrar num só processo a solução de um conflito difuso, coletivo ou individual homogêneo. Trata-se, como se percebe, de mais uma forma de fragmentar o poder da coisa julgada da ação coletiva, nos mesmos moldes da referida reforma do art. 16 da Lei da Ação Civil Pública.

${ }^{12}$ NEGRÃO, Ricardo. Ações coletivas: enfoque sobre a legitimidade ativa. São Paulo: Liv. e Ed. Universitária de Direito, 2004, p. 200-201, grifo do autor.

13 Ibid., p. 203-204. 
A grande vantagem do microssistema normativo brasileiro foi que, ao mesmo tempo em que ampliou os espaços políticos de atuação judicial da sociedade civil concebida a partir de uma perspectiva solidária de grupo e plural, já tinha criado as bases materiais para a ocupação desses espaços, pelo menos no plano teórico, diferentemente do que ocorreu, por exemplo, na Espanha, conforme explica Carlos Lasarte Álvarez ${ }^{14}$.

Está fuera de duda, por cuanto hemos resumido anteriormente, que el ejercicio de acciones colectivas por parte das de las asociaciones de consumidores se enmarca o encuadra en el movimiento europeo pro consumidor. Sin embargo, lo cierto es que la previsión normativa de la Ley General para la defensa de los consumidores y usuarios, al tiempo que representaba una absoluta novedad en nuestro ordenamiento jurídico, planteaba la dificultad de su aplicación práctica, pues las disposiciones procesales vigentes no fueron objeto de reforma alguna por parte de la LCU y se encontraban asentadas en principios y reglas característicos de la acción o intervención individual.

Em outras palavras, com a aprovação da Ley General para la Defensa de los Consumidores y Usuários, de 1984, conquanto se tenha conseguido expandir a legitimação ativa para a propositura das ações coletivas para as associações de consumidores, no plano concreto, não houve mudança no processo em si ou o surgimento de um mecanismo judicial que viabilizasse tal importante conquista.

A legitimação das "class actions" norte-americanas distancia-se da concepção da lei brasileira, na medida em que no direito estadunidense o legitimado não é prédefinido, mas decorre de uma análise efetiva do juiz (dotado de poderes amplos) da representação adequada daquele que se apresenta como legitimado (que deve ser, necessariamente, um dos membros que compõe o grupo). A verificação dessa "adequação" será realizada pela análise de vários requisitos rigorosos e que, uma vez certificada a ação como "coletiva", a coisa julgada dela decorrente atingirá a todos, indistintamente e independentemente do resultado.

A legitimação estabelecida pela lei brasileira, diferentemente do que ocorre no processo civil tradicional (no qual, sendo o interesse auferido em relação a um sujeito, procura-se normalmente atribuir-lhe, em decorrência dessa sua titularidade do interesse, a sua legitimação), não foi definida com base na própria conceituação do

\footnotetext{
${ }_{14}$ ÁLVAREZ, Carlos Lasarte. Manual sobre protección de consumidores y usuários. Madrid: Dykinson, 2010, p.
} 342. 
interesse jurídico processual, distanciando-se (de modo a tornar o direito de ação e o atuar processual ainda mais abstrato) da relação jurídica de direito material. De fato, o que norteou a opção legislativa foi o critério de representação adequada (claramente inspirada em instrumentos do direito comparado, mormente a class action norte-americana). ${ }^{15}$

Prossegue Negrão ${ }^{16}$,

A noção de adequação da representação distanciou-se do modelo inspirador (o norte-americano) na medida em que houve expressa determinação legal prévia, ensejando, assim, o reconhecimento "a priori" (exceto nos casos em que a lei exige a coincidência da finalidade institucional e a existência por mais um ano) dos adequados legitimados. Assim, reconhecemos que a questão da adequação, no caso da ação coletiva brasileira, vincula-se a um aspecto objetivo, qual seja, da pretensão legal de erigir aqueles que teriam melhores condições de proteger o interesse e não os sujeitos eventualmente vinculados com o direito coletivo. Por essa razão que a coisa julgada da ação coletiva brasileira dá-se apenas para favorecer o indivíduo e nunca prejudicá-lo (exceto no caso deste intervir como assistente litisconsorcial).

Optou a lei, assim, por eleger determinados entes, que por sua posição social, política e jurídica, têm condições de serem apontados como os únicos titulares daquele jeito de ação coletiva, para que a prestação jurisdicional seja eficaz.

Como se observou supra, no Brasil, para a averiguação da legitimação coletiva, é suficiente o exame do texto da lei. Não poderia o magistrado, por exemplo, afirmar que um ente legalmente legitimado não tem, em determinado caso, o direito de conduzir o processo. Neste caso, o legislador teria estabelecido um rol legal taxativo de legitimados, firmando uma presunção absoluta de que seriam "representantes adequados", não cabendo ao magistrado fazer essa avaliação caso a caso. $^{17}$

Para Didier e Zaneti ${ }^{18}$ : "A verificação da adequacy of representation seria tarefa do legislador. A legitimação coletiva seria, pois, ope legis.".

Todavia, há o argumento contrário de que a análise da legitimidade deveria

\footnotetext{
${ }_{15}$ NEGRÃO, 2004, p. $203-204$.

${ }^{16}$ NEGRÃO, loc. cit.

${ }^{17}$ DIDIER JR., Fredie; ZANETI JUNIOR, Hermes. Curso de Direito Processual Civil: processo coletivo. 4.ed. Salvador: JusPodium, 2009, p. 204-205.

${ }^{18}$ DIDIER JR.; ZANETI, loc. cit.
} 
ser critério semelhante definido pela legislação federal norte-americana, onde se exerce o verdadeiro controle judicial daquilo que seria a "representatividade adequada". Em outras palavras, permite-se que o magistrado possa examinar e controlar a legitimação coletiva no caso concreto, conforme as características do legitimado. ${ }^{19}$

No direito estadunidense, há a exigência de que o legitimado seja um membro do grupo e apresente características próprias que lhe determinem como adequado representante do grupo, como uma espécie de seleção prévia para a eventual certificação da ação. Para esses autores, a legitimação no Brasil, mesmo dos entes públicos, deveria passar por um filtro judicial, pois não bastaria a previsão legal da legitimação. Parte-se da premissa de que não é razoável imaginar que uma entidade, pela simples circunstância de estar autorizada em tese para a condução de processo coletivo, possa propor qualquer demanda coletiva, pouco importando suas peculiaridades. ${ }^{20}$

Didier e Zaneti ${ }^{21}$ complementam o raciocínio.

É preciso verificar, a bem de garantir a adequada tutela destes importantes direitos, se o legitimado coletivo reúne os atributos que o tornem representante adequado para a melhor condução de determinado processo coletivo, devendo essa adequação ser examinada pelo magistrado de acordo com critérios gerais, preferivelmente previamente estabelecidos ou indicados em juízo. Todos os critérios para aferição da representatividade adequada devem ser examinados a partir do conteúdo da demanda coletiva.

A análise de legitimação coletiva e da própria ideia de representação adequada ocorreria em duas etapas:

Primeiramente, verifica-se se bá autorização legal para que determinando ente possa substituir os titulares coletivos. A seguir, o juiz faz o controle in concreto da adequação da legitimidade para aferir, sempre motivadamente, se estão presentes os elementos que asseguram a representatividade adequada dos direitos em tela. ${ }^{22}$

\footnotetext{
${ }^{19}$ DIDIER JR.; ZANETI, loc. cit.

${ }^{20}$ DIDIER JR.; ZANETI, 2009, p. 205.

${ }^{21}$ DIDIER JR.; ZANETI, loc. cit.

${ }^{22}$ Ibid., p. 206, grifo nosso.
} 
No Brasil, como referido acima, a aferição da representação adequada decorre de expressa previsão legal, justamente para se evitar eventual discricionariedade judicial na avaliação da capacidade técnica do legitimado para a defesa dos interesses transindividuais envolvidos na demanda.

\section{AS MAZELAS DA SUPERDEPENDÊNCIA DOS LEGITIMADOS EXTRAORDINÁRIOS AO PRETENSO IMPULSO OFICIAL DO JUDICIÁRIO NA MOVIMENTAÇÃO DO PROCESSO}

O Conselho Nacional de Justiça - CNJ emite um relatório anual sobre a atividade do Judiciário no Brasil, o relatório "Justiça em Números" ${ }^{23}$ Dentre uma série de estatísticas analisadas e sistematizadas nos mais diversos níveis do Poder Judiciário brasileiro - o relatório abrange todas as esferas da justiça brasileira, excluindo apenas o Supremo Tribunal Federal. Nesse sentido, o presente estudo tomará como referência ilustrativa a pulverização das demandas individuais por danos morais nas relações de consumo. ${ }^{24}$

Vê-se que as indenizações por dano moral no Direito do Consumidor correspondem ao quarto maior assunto em número de demandas em todo o Poder Judiciário brasileiro, correspondendo a 3,94\% (1.667.654 de processos) de todos os processos ingressados no Poder Judiciário no ano de 2015. Nesses percentuais não estão inclusos os pedidos de indenizações no âmbito do direito civil ( $5^{\mathrm{a}}$ posição $2,13 \%$ ) e no direito do trabalho ( $7^{\mathrm{a}}$ posição - $1,74 \%$ ), que são contabilizados em separado. Outro dado importante dentro do contexto geral, é que a indenização por danos materiais figura apenas na $12^{\mathrm{a}}$ posição (1,24\% dos processos), e as demandas por danos materiais dentro do direito do consumidor nem figuraram entre os 20 primeiros assuntos. ${ }^{25}$

Essa litigância massificada decorre da crença de que o consumidor deverá insistir na lógica equivocada das recompensas indenizatórias imediatas e individuais, em detrimento da jurisdição civil coletiva, completamente subutilizada pelos legitimados extraordinários do artigo 82 do Código de Defesa do Consumidor -

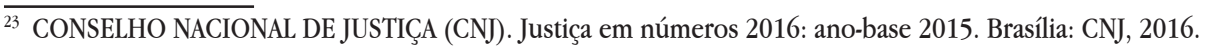

${ }^{24}$ A análise apresentada neste artigo tem como parâmetro o relatório publicado no ano de 2016, que teve como referência para análise $\mathrm{o}$ ano de 2015.

${ }^{25}$ CONSELHO NACIONAL DE JUSTIÇA (CNJ), 2016, p. 74. 
CDC e art. $5^{\circ}$ da Lei de Ação Civil Pública - LACP e mal gerida por um Judiciário excessivamente conservador no reconhecimento dos interesses transindividuais, que as julga a partir dos mesmos parâmetros interpretativos do vetusto individualismo jurídico, como se observa, por exemplo, com o instituto do dano moral coletivo, incapaz de ser compreendido a partir de uma perspectiva de grupo e, muitas vezes, a partir de uma fruição indivisível de natureza abstrata.

Há que ressaltar, também, o grave problema de acompanhamento das ações coletivas, independente de quem seja a entidade autora (associações de consumidores, Ministério Público, ou qualquer outro legitimado coletivo), o que ocorre em vários Estados da federação, pois se nota uma preocupação maior com as tutelas de urgência, ou mesmo de evidência, do que com o julgamento do mérito em si, assim como a execução ou cumprimento de eventuais decisões favoráveis.

Nesse particular, Heloisa Carpena ${ }^{26}$ externa sua preocupação com a falta de efetividade das ações coletivas em pesquisa realizada no acervo do TJRJ.

Em levantamento realizado no acervo do TJRJ, em decisões transitadas em julgado, proferidas em ações civis públicas propostas pelo Ministério Público para a defesa de interesses do consumidor, em apenas 3\% dos processos haviam sido ajuizadas execuções coletivas com fundamento no artigo 100 do CDC. O número de feitos em que foram encontradas execuções individuais também é insignificante.

Defende a autora que, mesmo nas hipóteses em que as práticas ilícitas no âmbito coletivo são reconhecidas pelo Judiciário, os agentes econômicos muito dificilmente são compelidos às restrições e indenizações a que são condenados. ${ }^{27}$

Após o ajuizamento da ação, pouco tem sido feito para se conseguir a concessão e/ou manutenção das tutelas de cognição sumária, sobretudo no âmbito recursal, sendo as ações abandonadas ao mero impulso oficial, no âmbito das varas privativas de feitos da fazenda pública. E como estão abarrotadas, com estrutura operacional deficiente e reduzidíssimo quadro de pessoal, não é difícil deduzir que o tempo excessivo de espera comprometerá o resultado prático do processo.

Como resultado desse cenário, muito dificilmente uma ação civil pública

\footnotetext{
${ }^{26}$ CARPENA, Heloísa. Consumidor Vencedor: um projeto do Ministério Público do Rio de Janeiro em busca da efetividade na defesa dos interesses individuais homogêneos dos consumidores. Revista de Direito do Consumidor, São Paulo, ano 22, vol. 86, mar./abr. 2013, p. 96.

${ }^{27}$ Ibid., p. 99.
} 
tem um desfecho meritório e é ainda mais raro identificar a execução ou mesmo cumprimento de uma sentença condenatória, o que acaba por favorecer o fornecedor que, agindo na infralegalidade, se locupleta indevidamente à custa do consumidor por práticas abusivas e outros comportamentos ilícitos.

E, justamente, pela demora e falta de efetividade da ação coletiva, aqui entendida como uma das últimas esperanças na correção de tantas distorções do mercado de consumo pelo Judiciário, é fortalecida a crença de que o processo atua para reforçar o status de superioridade jurídica e econômica do fornecedor em relação ao consumidor vulnerável e, muitas vezes, hipossuficiente.

A diversidade de atores coletivos, além de multiplicar exponencialmente as vias de discussão política no Judiciário, gera salutar competição entre os legitimados, obrigando-os a exercer uma fiscalização informal recíproca, pelos debates constantes e pela própria exigência de prestação de contas junto à sociedade civil, aqui ocupante de poder decisório dos mais relevantes, como já evidenciado pela atuação qualificada das Associações Representativas de Defesa do Consumidor.

Outrossim, seria importante dotar os legitimados oficiais, aqui entendidos como os que têm um braço do poder público, como o Ministério Público, a Defensoria Pública, entidades federativas de mecanismos mais eficazes de acompanhamento processual, para que não se acomodem com as prerrogativas da fazenda pública de que gozam em juízo e, por isso, passem a negligenciar os interesses que estão substituindo nas demandas coletivas.

Os atores coletivos precisam atuar como se fossem verdadeiros advogados da coletividade de consumidores, com interesse real e permanente na obtenção de um resultado rápido e satisfatório da lide e não apenas aumentar a estatística de ações ajuizadas ou usufruir da fama midiática que a propositura de algumas ações coletivas pode oferecer.

Essa exigência despertou para o surgimento da própria ideia de jurisdição civil coletiva, vindo a ser um reflexo da necessidade premente erigida no bojo da sociedade de consumo, marcada por relações de massa. Essa sociedade clama pela solução equânime de conflitos dispersos, sendo certo que sua estrutura inaugurou uma nova conceituação da relação jurídica processual e do próprio direito de ação. ${ }^{28}$

Negrão ${ }^{29}$ sustenta que

\footnotetext{
${ }^{28}$ NEGRÃO, 2004, p. $297-298$.

${ }^{29}$ Ibid., p. 299.
} 
A ação coletiva possui papel importante na busca da efetividade da jurisdição, na medida em que, de um lado, representa um meio de se fazer valer uma amplitude nos limites da coisa julgada (e, portanto, possível ampliação subjetiva dos efeitos concretos dessa mesma coisa julgada) significando, com isto, maior acesso à justiça e, de outro lado, contribui para a economia processual (apenas uma decisão, várias relações tuteladas).

Outra mudança relevante viria do próprio Judiciário, seja pela imposição de metas de julgamento das ações coletivas (Meta $n^{0} 6$ do Conselho Nacional de Justiça), ou pela descentralização no julgamento das ações pelas varas privativas, o que pulverizaria a competência regimental para todas as demais varas cíveis, garantindo maior fluidez nos julgamentos. ${ }^{30}$

Em meio a essas questões, exsurge a vulnerabilidade do consumidor nas relações de consumo, como uma das principais preocupações da sociedade pósmoderna, que se vê inserida num processo mundial de globalização, avanços tecnológicos, difusão do crédito irresponsável, massificação dos contratos, propagação de práticas comerciais abusivas, desafiando a intervenção dos órgãos integrantes da Política Nacional das Relações de Consumo, obrigando a todos os legitimados coletivos a ocuparem o seu papel, incluindo-se aí as entidades federativas, por meio de seus órgãos procuratórios, que, por questões políticas e administrativas, ainda não assumiram tal relevante compromisso social em prol de um modelo de consumo sustentável pela via processual coletiva.

Isso porque já há a participação do Estado, mesmo que de maneira transversa, por meio do Procon (Grupo Executivo de Proteção ao Consumidor), órgão que pode ser municipal ou estadual, integrando a administração direta, que exerce poder de polícia fiscalizatório e, ao mesmo tempo, presta atendimento individual ao consumidor, mas que tem se mostrado inoperante quanto à propositura das ações coletivas. Prerrogativa essa consagrada nos artigos $5^{\circ}$, caput da lei. 7.347/85 (LACP) e 82, II do CDC, in literis:

Art. $5^{\circ}$ - A ação principal e a cautelar poderão ser propostas pelo Ministério Público, pela União, pelos Estados e Municípios. [...] (Lei 7.347/85)

\footnotetext{
${ }^{30}$ Neste particular, cite-se a meta $\mathrm{n}^{0} 18$ do Conselho Nacional de Justiça (CNJ), relativa ao julgamento das ações de improbidade administrativa e crimes contra a administração pública.
} 
Art. 82- Para fins do art. 81, parágrafo único, são legitimados concorrentemente:

$[\ldots]$

II- a União, os Estados, os Municípios e o Distrito Federal (CDC).

Não se admite que o microssistema de proteção ao consumidor, que cria um mecanismo excepcional de defesa coletiva, tornando eficaz, célere e efetiva a tutela processual do consumidor, possa ser desprestigiado por alguns dos legitimados extraordinários.

Deve-se esclarecer, todavia, que o Ministério Público não possui uma legitimidade preferencial para agir na defesa dos interesses metaindividuais do consumidor, como equivocadamente se convencionou acreditar na sociedade, mas todas as entidades mencionadas nos dispositivos supra, inclusive as entidades federativas, em nome próprio, ou pelo Procon, poderão ajuizar a competente ação coletiva para a defesa dos interesses transindividuais.

Todos os avanços e inovações jurídicas trazidos à discussão com a consolidação do microssistema de proteção ao consumidor (CDC, LACP etc), que tornam mais efetiva a tutela e aumentam sobremaneira as possibilidades de êxito nas demandas, poderão ser manejadas pelas entidades federativas, sem qualquer ônus adicional em suas finanças, bastando, todavia, alargar as competências institucionais dos respectivos órgãos procuratórios.

Tem-se, na verdade, por meio da Ação Civil Pública, um instrumento importantíssimo para que se alcance a tão almejada harmonia das relações de consumo.

Quando se fala em harmonia, se quer, de fato, estabelecer um padrão de comportamento para as empresas que atuam no mercado, disponibilizando produtos e serviços, que nem sempre estão de acordo com as reais expectativas do consumidor e nem tampouco, com os rigorosos índices de qualidade, quantidade e preço, consubstanciados na Política Nacional de Defesa do Consumidor.

Problemas corriqueiros se multiplicam no país, sem que haja efetiva participação dos órgãos públicos, onde a intervenção quase que exclusiva do Ministério Público e da Defensoria Pública acaba sendo insuficiente para dirimi-los.

A título de ilustração, um dos maiores índices de reclamação e insatisfação do consumidor, tanto nos Procons, quanto nas Defensorias Públicas e Promotorias 
de Defesa do Consumidor de vários Estados da federação corresponde aos serviços essenciais, concedidos à iniciativa privada, tais como telefonia celular, energia, transporte público etc.

Nesses casos, a iniciativa de ações coletivas se perde em meio a uma opção de atuação pulverizada dos órgãos na defesa de interesses individuais subjetivos, sem falar do alcance limitado das ações coletivas propostas, cujo acompanhamento de sua evolução processual e efeito prático também se revelaram deficientes.

Quanto à ineficiência dos serviços públicos, pesa ainda a crítica de que as Agências reguladoras (ANS, ANAC, Anatel, Aneel etc.) nada têm feito a esse respeito, ressaltando-se que essa inércia torna-se mais gritante, quando se verifica que é o próprio Estado o poder concedente dos mesmos, cabendo-lhe, também e, sobretudo, a fiscalização de como têm sido disponibilizados à sociedade.

As sanções administrativas são várias, as multas contemplam valores astronômicos, mas se não são aplicadas, indaga-se: poderá o consumidor ser responsabilizado pela má execução dos serviços e continuar aguardando por uma medida enérgica que nunca vem?

É óbvio que não, revelando-se como alternativa mais viável e adequada no momento o controle repressivo exercido na esfera judicial, por meio das ações coletivas, para que, mais tarde, seja implementado, também, um controle preventivo, pelo amadurecimento cívico pelo debate político proposto pelo novo modelo de solidariedade.

A legitimidade das entidades federativas para a propositura das referidas ações sempre existiu, embora jamais tenha sido utilizada, eis que resta descrita no art. $5^{\circ}$, caput da lei $7.347 / 85$, já transcrito supra, bem como no art. $5^{\circ}$, XXXII da Constituição Federal, in literis: "O Estado promoverá na forma da lei, a defesa do consumidor.".

A doutrina também prestigia a iniciativa do Estado de intervir na tutela dos interesses coletivos do consumidor, senão vejamos o que ensina Carvalho Filho ${ }^{31}$.

A lei legitima também, para ação civil pública, a União, os Estados e os Municípios. Sua legitimidade provém, obviamente, de seu status dentro do contexto jurídico-político vigente. Trata-se de pessoas que integram a própria federação (arts. $1^{\circ}$ e 18, da CF) e, em consequência, devem Ter interesse

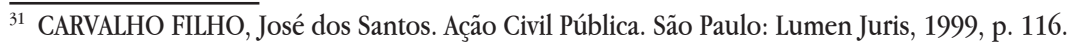


na tutela de direitos coletivos e difusos da coletividade que representam. Sendo integrantes da federação, tais entidades são dotadas de capacidade de autoadministração, razão porque poderão dispor-se, em muitas ocasiões, à proteção dos interesses grupais.

Independente da forma de atuação das entidades federativas, em nome próprio, ou através dos Procons estaduais ou municipais, faz-se necessária uma articulação eficiente para com estes, tendo em vista as inúmeras vantagens daí decorrentes.

Por exemplo, as reclamações naquele órgão formuladas poderiam ter uma função sinalizadora das questões mais frequentes e de maior relevância para a coletividade, bem como instruir as eventuais ações coletivas, formando a convicção do juízo, de maneira mais contundente e aumentando as possibilidades de êxito, tanto em sede de provimentos de cognição sumária, como na apreciação do próprio mérito da ação.

Outro ponto extremamente vantajoso para o Estado e que torna a consecução dessa iniciativa uma alternativa bastante viável, em curto espaço de tempo, é o fato de inexistir ônus financeiro para o poder público.

Como mencionado supra, no primeiro momento, a estrutura a ser empregada é mínima, para não dizer que inexiste, porquanto bastaria a criação de um pequeno núcleo ${ }^{32}$ de procuradores e alguns servidores que assumiriam a responsabilidade pelos estudos, elaboração, manejo e acompanhamento das ações, sem qualquer ônus adicional para o Estado, até porque a ideia prescinde de recursos financeiros e já seria autoexecutável quanto aos recursos humanos.

Da mesma forma, as eventuais demandas coletivas seriam registradas normalmente no cadastro interno de arquivo e acompanhamento processual, o que, em muitas entidades, já é totalmente virtual, tendo um trâmite administrativo regular, idêntico a qualquer outro processo da competência originária dos respectivos órgãos.

\section{ISENÇÃO DE CUSTAS E HONORÁRIOS SUCUMBENCIAIS NAS AÇÕES COLETIVAS}

$\overline{32}$ Esse núcleo poderia ser ampliado paulatinamente conforme fosse crescendo a demanda. 
Sobre custas processuais e ônus da sucumbência, já há um entendimento uniforme na doutrina e na jurisprudência de que não são devidos em face da entidade autora, salvo nos casos de comprovada a má-fé, até porque a legislação toda segue essa linha de raciocínio. Neste particular, o microssistema normativo de defesa do consumidor assim dispõe:

Art. 18- Nas ações de que trata esta Lei, não haverá adiantamento de custas, emolumentos, honorários periciais e quaisquer outras despesas, nem condenação da associação autora, salvo comprovada a má fé, em honorários de advogados, custas e despesas processuais. (Lei 7.347/85).

Art. $6^{\circ}$ - São direitos básicos do consumidor:

$[\ldots]$

VII- acesso aos órgãos judiciários e administrativos, com vistas à prevenção ou reparação de danos patrimoniais e morais, individuais, coletivos ou difusos, assegurada a proteção jurídica, administrativa e técnica aos necessitados." (Lei 8.078/90-CDC)

A mens legis de tais dispositivos espelha-se no fato de que o risco de condenação em custas e honorários advocatícios poderia desestimular a propositura das ações, o que, por certo, não se coaduna com as finalidades da Constituição, do CDC e da LACP, dentre as quais está o acesso facilitado à justiça.

O próprio Ministério Público tem se utilizado desses dispositivos para exonerar-se da obrigação de arcar com o ônus da sucumbência, quando do julgamento desfavorável das ações, salvo nos casos de comprovada má-fé.

A jurisprudência brasileira é farta quanto à questão.

AÇÃO CIVIL PÚBLICA. SENTENÇA DE IMPROCEDÊNCIA. CONDENAÇÃO DO MINISTÉRIO PÚBLICO EM CUSTAS E HONORÁRIOS PERICIAIS DESCABIDA. O Ministério Público, na ação civil pública, atuando como substituto processual da sociedade, está isento do pagamento das custas, despesas e honorários profissionais. Inteligência dos artigos 17 e $18 \mathrm{da}$ Lei $\mathrm{n}^{\circ} 7347 / 85$, com a redação dada pelo art. 115 da Lei $\mathrm{n}^{\circ}$ 8078/90, e artigo $5^{\circ}$, inciso LXXIII, da Constituição Federal. Apelo provido. ${ }^{33}$

PROCESSUAL. DUPLICIDADE DE RECURSOS ESPECIAIS.

33 BRASIL. Tribunal de Justiça do Rio Grande do Sul. Apelação cível n 597023654 . Relator: Des. João Armando Bezerra Campos, 1999. 
IMPOSSIBILIDADE. AÇÃO CIVIL PÚBLICA. MINISTÉRIO PÚBLICO. HONORÁRIOS. CUSTAS. MÁ-FÉ. A parte não tem o direito de interpor dois recursos especiais para impugnar o mesmo acórdão, a não ser na hipótese de embargos infringentes. O Ministério Público não pode responder por honorários de advogado, custas e despesas processuais, em ação civil pública, a não ser quando age com má-fé. Só neste caso a Fazenda Pública arcaria com os ônus da sucumbência. Recursos providos ${ }^{34}$

AÇÃO CIVIL PÚBLICA. HONORÁRIOS ADVOCATÍCIOS. MINISTÉRIO PÚBLICO.

I - Só no caso de o órgão ministerial agir com comprovada máfé, os ônus da sucumbência deverão ser carreados à Fazenda Pública. CPC, arts. 20, 27 e 81. Lei 7.437, de 24/07/1985, arts. 17,18 e 19. Precedentes.

II-Recurso Especial não conhecido. ${ }^{35}$

CAUTELAR INOMINADA. AÇÃO CIVIL PÚBLICA. RELAÇÃO DE CONSUMO. Incabível a condenação do Ministério Público, quando sucumbe nas custas judiciais, a menos que se comprove sua má-fé. Art. 18 da Lei 7343/85. Precedentes jurisprudenciais. Apelo provido. ${ }^{36}$

As prerrogativas da isenção de custas e do ônus da sucumbência beneficiam todos os legitimados ativos, incluindo-se aí a Fazenda Pública e as Associações Representativas quando agem com a mesma finalidade.

A LACP assume posição diametralmente oposta àquela adotada pelo CPC. Enquanto neste a regra é o adiantamento de custas e despesas processuais pelo autor ou parte que requereu o ato judicial (perícia, p.ex.), na ação civil prevalece regra em sentido oposto: não haverá adiantamento de custas e despesas processuais (LACP, art. 18). O que se explica pela natureza transindividual indivisível dos interesses difusos e coletivos e pela relevância social dos individuais homogêneos. Idêntico procedimento é adotado em relação à ação popular manejada pelo autor (qualquer cidadão) para anular ato lesivo ao patrimônio público, à moralidade administrativa, ao meio ambiente e ao patrimônio histórico e cultural (CF, art. $5^{\circ}$, LXXIII). ${ }^{37}$

Assim sendo, os riscos em hipótese de julgamento desfavorável nas ações

\footnotetext{
34 BRASIL. Superior Tribunal de Justiça. Recurso especial nº 120290. Relator: Min. Garcia Vieira, 1998.

${ }^{35}$ BRASIL. Superior Tribunal de Justiça. Recurso especial no 57162/MG. Relator: Min. Antônio de Pádua Ribeiro, 1996.

${ }^{36}$ BRASIL. Tribunal de Justiça do Rio Grande do Sul. Apelação cível no 70001646330 . Relator: Des. Sergio Pilla da Silva, 2000.

${ }^{37}$ ALMEIDA, 2001, p. 173.
} 
coletivas é mínimo, subsistindo apenas na hipótese de comprovada má-fé da entidade autora.

\section{POSSIBILIDADE DE INVERSÃO DO ÔNUS DA PROVA NAS DEMANDAS COLETIVAS}

O instituto da inversão do ônus da prova previsto no artigo $6^{\circ}$, VIII do CDC surge como uma das grandes inovações propostas pelo legislador consumerista como incentivo a maior participação democrática do consumidor junto ao Judiciário.

A inversão se identifica porque há a fragilidade técnica e jurídica natural do consumidor no momento de fazer prova do seu direito, justificando-se à medida que a relação processual fique num patamar de maior igualdade. É muito fácil para uma empresa que, via de regra, é bem assessorada do ponto de vista jurídico colocar no mercado um produto em condições adversas, excluir sua responsabilidade numa cláusula contratual, deixando o consumidor no prejuízo, até porque o processo civil tradicional, sobretudo o brasileiro, foi concebido para favorecer o réu e não ao autor. $^{38}$

Isso pode ser constatado quando se percebe a grande quantidade de recursos existentes, que contribuem para a demora na entrega da prestação jurisdicional, além de outros fatores obstativos à instrumentalidade e celeridade processuais, violando, assim, princípios basilares como o da razoável duração do processo, previsto no artigo $5^{\circ}$, inciso LXXVIII, da CF/88.

Essa instabilidade pré-processual do consumidor acaba por atingir o princípio da segurança jurídica, pela ineficiência do aparelho judicial do Estado, pois um consumidor, na condição de autor, dificilmente, se sentirá à vontade para buscar a discussão daquele direito na via judicial, eis que se torna mais fácil e menos desgastante a resignação, ou seja, a postura indolente que o advento da solidariedade se propôs a corrigir.

A inversão do ônus da prova, como instrumento de facilitação do acesso à justiça, está prevista no art. $6^{\circ}$, VIII do CDC, in litteris:

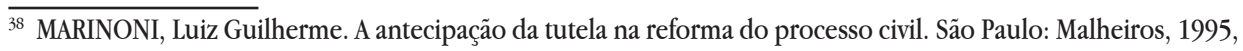
p. 79. 
Artigo $6^{\circ}$ São direitos básicos do consumidor:

$[\ldots]$

VIII- a facilitação da defesa dos seus direitos, inclusive com a inversão do ônus da prova, a seu favor, no processo civil, quando, a critério do juiz, for verossímil a alegação ou quando for ele hipossuficiente, segundo as regras ordinárias de experiência.

Com efeito, pela leitura do dispositivo legal, observa-se que os requisitos para a inversão do ônus da prova são objetivos e alternativos, seja nas hipóteses de verossimilhança das alegações, seja o consumidor hipossuficiente, sendo esta verificação uma regra de julgamento.

Neste sentido, é o entendimento do Superior Tribunal de Justiça. ${ }^{39}$ Conferir.

Ementa

RECURSO ESPECIAL. DIREITO DO CONSUMIDOR. INVERSÃO DO ÔNUS DA PROVA. MOMENTO. SENTENÇA. POSSIBILIDADE. REGRA DE JULGAMENTO. OFENSA AO PRINCÍPIO DO CONTRADITÓRIO. INEXISTÊNCIA.

1. A jurisprudência do STJ não se pacificou quanto à possibilidade de o juízo inverter o ônus da prova no momento de proferir a sentença numa ação que discuta relação de consumo.

2. O Processo Civil moderno enfatiza, como função primordial das normas de distribuição de ônus da prova, a sua atribuição de regular a atividade do juiz ao sentenciar o processo (ônus objetivo da prova). Por conduzirem a um julgamento por presunção, essas regras devem ser aplicadas apenas de maneira excepcional.

3. As partes, no Processo Civil, têm o dever de colaborar com a atividade judicial, evitando-se um julgamento por presunção. Os poderes instrutórios do juiz lhe autorizam se portar de maneira ativa para a solução da controvérsia. As provas não pertencem à parte que as produziu, mas ao processo a que se destinam.

4. O processo não pode consubstanciar um jogo mediante o qual seja possível às partes manejar as provas, de modo a conduzir o julgamento a um resultado favorável apartado da justiça substancial. A ênfase no ônus subjetivo da prova implica privilegiar uma visão individualista, que não é compatível com a teoria moderna do processo civil.

$\overline{39}$ BRASIL. Superior Tribunal de Justiça. Recurso Especial nº 1125621/MG. Relatora: Min. Nancy Andrighi, 2011. 
5. Inexiste surpresa na inversão do ônus da prova apenas no julgamento da ação consumerista. Essa possibilidade está presente desde o ajuizamento da ação e nenhuma das partes pode alegar desconhecimento quanto à sua existência.

6. A exigência de uma postura ativa de cada uma das partes na instrução do processo não implica obrigá-las a produzir prova contra si mesmas. Cada parte deve produzir todas as provas favoráveis de que dispõe, mas não se pode alegar que há violação de direito algum na hipótese em que, não demonstrado o direito, decida o juiz pela inversão do ônus da prova na sentença.

7. Recurso especial conhecido e improvido.

A partir das explicações supra é possível concluir que: a) a inversão do ônus da prova não é uma decisão pessoal ou subjetiva do juiz; b) não é uma decisão automática, até porque existem dois requisitos de ordem objetiva que vão fundamentar e balizar a atuação do magistrado; c) a inversão não exige a coexistência dos dois requisitos, basta que haja apenas um.

Veja-se a seguinte situação: uma consumidora possuía um cartão de crédito "x". Efetuou o pagamento de sua fatura mensal por meio de cheque, dentro do vencimento, nominal à respectiva Administradora do Cartão. Ocorre, todavia, que esse crédito não foi compensado pela administradora, por circunstâncias estranhas ao conhecimento da consumidora, que passou a receber a cobrança retroativa desse período com juros, encargos etc. Irresignada e buscando demonstrar sua boa-fé, a consumidora encaminha uma carta à administradora, solicitando providências, juntando a cópia do cheque (se deu ao trabalho de retirar a cópia do cheque), bem como da fatura com a devida autenticação mecânica. Para sua surpresa, a administradora recusa o crédito alegando que o documento encaminhado não tinha credibilidade para justificar a compensação. Nessa hipótese, está mais do que caracterizada a verossimilhança das alegações da consumidora, autorizando, portanto, a consequente inversão do ônus da prova.

Imagine-se outra situação, em que, dessa vez, a hipossuficiência se faz presente. É muito comum, hoje em dia, o consumidor efetuar seus pagamentos por meio de terminais bancários de autoatendimento, em que se a leitura óptica não estiver funcionando, ele mesmo digita o número do código de barras do título etc. Nesse sentido, um consumidor idoso resolve efetuar o pagamento através desses terminais e, por desconhecimento técnico, digita incorretamente os números 
do respectivo título de cobrança, vindo a ter prejuízos pela não compensação do documento, promovendo a devida ação judicial de indenização. Numa discussão judicial, o banco alegaria culpa exclusiva do cliente, porque digitou o número errado e, por essa razão, não foi possível fazer a compensação do pagamento.

Logicamente, a pretensão do consumidor acabará por prevalecer, pois não se concebe que um banco possa disponibilizar um sistema de atendimento falho, não alocando um funcionário para, pelo menos, orientar o consumidor que, no caso, tinha problemas de saúde ou de compreensão, impedindo-o de manusear corretamente o terminal. Destarte, como o banco não disponibilizou um serviço e/ ou atendimento eficaz, acaba por assumir o risco por eventuais prejuízos causados ao consumidor.

$\mathrm{O}$ fato de o CDC imputar ao fornecedor a responsabilidade pelo risco do negócio não significa uma perseguição ao fornecedor, mas visa apenas proteger aquele que precisa de um cuidado maior, tanto do ponto de vista material, com a proteção dos direitos básicos, quanto do ponto de vista formal-processual, no aspecto da hipossuficiência, em que se percebe a dificuldade de provar suas alegações; ter acesso adequado e seguro aos serviços e produtos, ou, até mesmo, compreender juridicamente o alcance de suas obrigações.

Ademais, a análise da inversão do ônus da prova deverá ser realizada em cotejo com o princípio da boa-fé objetiva, que produz em favor do consumidor uma necessária presunção de boa-fé acerca de suas alegações, porquanto frustradas suas reais expectativas de consumo.

Importa saber acerca da aplicação do instituto às ações coletivas, porquanto a grande maioria dos substitutos processuais tem a mesma ou até maior experiência processual que o fornecedor, gozando ainda de prerrogativas diferenciadas, como aquelas conferidas à Fazenda Pública em juízo, tais como prazos em dobro para recorrer, isenção de todas as custas processuais, intimação pessoal etc.

Nessa linha de raciocínio, o substituto muito dificilmente poderá ser considerado hipossuficiente e, se a mens legis do dispositivo foi criar maior equilíbrio processual, a inversão do ônus da prova em ação coletiva poderia pender a balança de modo a comprometer não apenas o equilíbrio no processo, mas as próprias garantias constitucionais do devido processo legal, a ampla defesa e o contraditório do fornecedor, previstas, respectivamente, nos incisos LIV, LV do artigo $5^{\circ}$ da Constituição Federal de 1988, sobretudo se for deferida de modo genérico e sem a 
observância dos requisitos legais.

A questão deverá ser enfrentada em duas etapas.

Em primeiro lugar, o substituto processual não é parte e nem titular do interesse discutido na ação, daí porque a análise dos requisitos legais para o deferimento da inversão deverá se concentrar nos substituídos, o que, dependendo do caso, poderia favorecer a inversão, embora se reconheça que não será automática.

Em segundo lugar, uma eventual violação das garantias constitucionais não decorre, a priori, do deferimento da inversão do ônus da prova em ação coletiva, mas da não observância dos parâmetros legais da medida, o que pode ocorrer tanto nas demandas coletivas, como também nas individuais.

Desse modo, observados, alternativamente, os requisitos legais da verossimilhança das alegações ou hipossuficiência e especificada a prova cujo ônus se deseja inverter, independente do alcance da ação (se individual ou coletiva), a medida poderá ser deferida, inclusive para efeito de ônus financeiro da prova, nas hipóteses em que o autor não possuir condições de arcar com os honorários para realização de prova pericial técnica, como costuma ocorrer com algumas associações representativas de defesa do consumidor.

O Anteprojeto de Código Brasileiro de Processos Coletivos enfatiza fórmula que atribui o ônus da prova à parte que detiver conhecimentos técnicos ou informações específicas sobre os fatos ou maior facilidade em sua demonstração. Caberia, assim, às partes, revelar os conhecimentos científicos e informações pertinentes ao caso, considerando não apenas as suas alegações, mas, também, as da parte contrária. A detenção dos conhecimentos técnicos ou informações específicas e a maior facilidade na demonstração passam a ser matéria, em potencial, controvertida e, portanto, prejudicial para a fixação do ônus da prova, que pode, em si, demandar a colheita de prova ou aplicação das regras de experiência. ${ }^{40}$

Trata-se da aplicação do princípio da aptidão para a prova, positivado no ordenamento jurídico brasileiro pelo artigo $373, \S 1^{\circ}$, do $\mathrm{CPC} / 15$, o qual permite que o juiz altere a regra de distribuição do ônus da prova prevista no caput e nos incisos do referido artigo (pautada na posição processual da parte - autor ou réu), nos casos em que houver impossibilidade ou excessiva dificuldade da parte em produzir a prova, ou quando houver maior facilidade de produção da prova do fato contrário, conforme preconizado no anteprojeto supracitado.

${ }^{40}$ DIDIER JR., Fredie; MOUTA, José Henrique (coord). Tutela Jurisdicional Coletiva. Salvador: JusPodium, 2009, p. 109. 
O princípio em apreço representa importante inovação processual, pois como o Código de Defesa do Consumidor não expressou a natureza do atributo pessoal da hipossuficiência, presente em alguns consumidores, dá margem a uma interpretação restritiva do seu alcance para abranger apenas os economicamente necessitados, o que já se viu ser tecnicamente equivocado, porquanto a premissa de inferioridade econômica não se aplica a tal atributo. Assim, nos casos concretos, mesmo que o juiz entenda que não seja cabível a aplicação da inversão do ônus da prova com base no CDC, em razão da ausência dos requisitos previstos em lei, o consumidor ainda poderá se valer do princípio da aptidão para a prova, que servirá de instrumento para garantir o equilíbrio processual.

Portanto, o deferimento da inversão do ônus da prova nas ações coletivas observará os mesmos critérios estabelecidos para as ações individuais, obrigando o órgão julgador a analisar minuciosamente a presença dos requisitos legais a partir das circunstâncias do caso, tais como as partes envolvidas, a natureza e o custo financeiro das provas, sua utilidade e repercussão para o convencimento final acerca do direito, e, em último caso, o julgador poderá aplicar o princípio da aptidão para a prova, sendo importante ferramenta de facilitação da defesa processual do consumidor em juízo.

\section{LITISCONSÓRCIO ATIVO ENTRE O MINISTÉRIO PÚBLICO FEDERAL E ESTADUAL}

$\mathrm{O} \S 2^{\circ}$ do art. 82 do CDC restou vetado pelo Presidente da República, dispositivo esse que admitia o litisconsórcio facultativo entre os Ministérios Públicos da União, do Distrito Federal e dos Estados na defesa dos interesses e direitos de que cuida o Código. Contudo, o $\S 5^{\circ}$ do art. $5^{\circ}$ da LACP admite essa possibilidade, aliás, com a mesma redação do dispositivo revogado no CDC. Nesse caso, indaga-se: se o CDC é omisso e a LACP permite, será possível o litisconsórcio?

Em primeiro lugar, mister identificar o porquê desta curiosidade. Muitas inovações trazidas pelo CDC foram incorporadas ao texto da LACP. Havia a possibilidade de litisconsórcio no anteprojeto de lei do $\mathrm{CDC}$, mas que restou vetada pelo Presidente da República. Entretanto, por um erro de publicação, esqueceramse de alterar a redação da LACP que autoriza essa atuação conjunta, razão pela qual 
entrou em vigor com um vício material no processo legislativo.

Concretamente, veja-se uma situação em que o Ministério Público Estadual recolheu subsídios para a propositura de uma ação civil pública e está melhor abalizado para a defesa daquele interesse. Entretanto, a competência é da Justiça Federal porque o dano é regional, o que justificaria uma parceria com o Ministério Público Federal, entidade capaz de viabilizar a propositura da ação. Como resultado da demanda haverá um número maior de consumidores beneficiados e não se desperdiçaria o material e as provas coletadas na esfera estadual de atuação do Ministério Público.

Desse modo, é possível defender tanto a impossibilidade do litisconsórcio pelo veto constante do CDC, quanto sua possibilidade em razão de constituir uma política de atuação eficaz pela previsão da Lei da Ação Civil Pública e também pela possibilidade adicional de se ampliar os efeitos da tutela coletiva.

Como argumentos em favor da tese, pode-se afirmar que a despeito da omissão do CDC e do vício material no processo legislativo, por inexistir vedação expressa na LACP, admitir-se-á o litisconsórcio. Além disso, a atuação conjunta do Ministério Público Federal e Estadual garantirá melhores possibilidades de êxito na demanda, porque maiores os elementos de convicção fornecidos ao juiz, no sentido de reconhecer a procedência da pretensão coletiva.

Entretanto, em sentido contrário, não se admitiria o litisconsórcio porque o Ministério Público seria uma instituição una e indivisível e que não poderia ser fracionada, sendo impossível conceber o litisconsórcio entre a mesma instituição, tese essa que não se sustenta, por caracterizar uma interpretação por demais formalista e restritiva para as finalidades sociais contempladas no CDC.

\section{CONCLUSÃo}

Atualmente, em tempos em que o cidadão se preocupa muito mais com o efeito coercitivo da decisão judicial e do que com a lei, como se esta precisasse sempre ser infirmada em sua validade por um juiz ou Tribunal, o Código de Defesa do Consumidor (lei 8.078/90) conserva seu status de norma de ordem pública e interesse social, pois esteve sempre na vanguarda e foi a porta de entrada para algumas das principais transformações pelas quais o direito brasileiro vem passando 
nas últimas décadas, o que gera segurança e estabilidade no âmbito das relações de consumo e vai além.

A previsão de uma vasta tutela material de direitos é blindada por sua base processual extremamente eficaz, concedendo ao consumidor individual e, principalmente, àquele concebido em sua feição coletiva, uma via democrática de acesso ao Judiciário, não como única expressão de participação política (o diálogo permanente nas políticas públicas para as relações de consumo e a articulação associativa nas convenções coletivas de consumo também cumprem este papel), mas essa abertura processual é a que melhor define o conceito de solidariedade para o direito.

$\mathrm{O}$ artigo demonstrou a necessidade de se rediscutir a legitimação extraordinária para a propositura das ações coletivas no âmbito da tutela do consumidor como importante espaço de atuação política qualificada, indevidamente ocupado e exercitado, muitas vezes, de forma equivocada, o que acaba por fomentar a crença do fornecedor de que agir na infralegalidade compensa e, da parte do consumidor, de que continuaria sendo a melhor alternativa investir em uma atuação individual e pulverizada perante o Judiciário, em busca de uma falseada lógica de recompensas econômicas concretas. Tudo, em detrimento do maior fortalecimento dos interesses de grupo, tão prestigiados pela vertente plural do direito do consumidor, mas que ante sua operacionalização deficiente, involuíram e perderam a capacidade de transformar a realidade social e econômica dos sujeitos da relação de consumo.

O Judiciário, por sua vez, intolerante e pouco eficaz nos mecanismos de resposta jurisdicional ao crescimento massificado das demandas individuais de consumo, , já se encontra no perigoso estágio da banalização das pretensões consumeristas, pois dada a sua recorrência, as ações individuais recebem a pecha de demandas aventureiras, numa proximidade incômoda ao clichê do "mero aborrecimento".

Conclui-se que a instrumentalização coletiva dos interesses do consumidor, por meio da articulação permanente e concertada dos legitimados ativos, exerceria uma força contra majoritária em relação aos detentores dos meios de produção, que seriam compelidos à mudanças substanciais nos padrões de qualidade e segurança dos bens de consumo, algo que a atuação acidental do consumidor pela via individual jamais conseguirá. 


\section{REFERÊNCIAS}

ALMEIDA, João Batista de. Aspectos controvertidos da ação civil pública:

doutrina e jurisprudência. São Paulo: Revista dos Tribunais, 2001.

ÁLVAREZ, Carlos Lasarte. Manual sobre protección de consumidores y usuários. Madrid: Editorial Dykinson, 2010.

BRASIL. Superior Tribunal de Justiça. Recurso especial $\mathbf{n}^{\mathbf{0}} \mathbf{1 7 2 . 2 3 7 / R S . ~ R e l a t o r : ~}$ Ministro César Asfor Rocha, 2000.

BRASIL. Tribunal de Justiça do Rio Grande do Sul. Apelação cível no 597023654. Relator: Des. João Armando Bezerra Campos, 1999.

BRASIL. Superior Tribunal de Justiça. Recurso especial $\mathbf{n}^{\mathbf{0}}$ 120290. Relator: Min. Garcia Vieira, 1998.

BRASIL. Superior Tribunal de Justiça. Recurso especial no 198827/SP. Relator: Min. José Delgado, 1999.

BRASIL. Superior Tribunal de Justiça. Recurso especial no 57162/MG. Relator: Min. Antônio de Pádua Ribeiro, 1996.

BRASIL. Superior Tribunal de Justiça. Recurso especial no 47242/RS. Relator: Min. Humberto Gomes de Barros, 1994.

BRASIL. Tribunal de Justiça do Rio Grande do Sul. Apelação cível $\mathbf{n}^{\mathbf{o}}$ 70001646330. Relator: Des. Sergio Pilla da Silva, 2000.

BRASIL. Superior Tribunal de Justiça. Recurso Especial no 1125621/MG. Relatora: Min. Nancy Andrighi, 2011.

BRASIL. Superior Tribunal de Justiça. Recurso especial no 949000/ES. Relator: Min. Humberto Gomes de Barros, 2008.

BUJOSA VADELL, Lorenzo. La protección jurisdicional de los intereses de grupo. Barcelona: José María Bosh, 1995.

CARPENA, Heloísa. Consumidor vencedor: um projeto do Ministério Público do Rio de Janeiro em busca da efetividade na defesa dos interesses individuais homogêneos dos consumidores. Revista de Direito do Consumidor, São Paulo, v. 86, ano 22, mar./abr. 2013.

CARVAlHO FILHO, José dos Santos. Ação Civil Pública. São Paulo: Lumen Juris, 
1999.

CONSELHO NACIONAL DE JUSTIÇA (CNJ). Justiça em números 2016: ano-base 2015. Brasília: CNJ, 2016.

DIDIER JR., Fredie; MOUTA, José Henrique (Coord). Tutela Jurisdicional Coletiva. Salvador: JusPodium, 2009.

DIDIER JR., Fredie; ZANETI JUNIOR, Hermes. Curso de Direito Processual Civil: processo coletivo. 4. ed. Salvador: JusPodium, 2009.

GIDI, Antônio. A coisa julgada e litispendência em ações coletivas. São Paulo: Saraiva, 1995.

LENZA, Pedro. Teoria Geral da Ação Civil Pública. São Paulo: Revista dos Tribunais, 2003.

MARINONI, Luiz Guilherme. A antecipação da tutela na reforma do processo civil. São Paulo: Malheiros, 1995.

NEGRÃO, Ricardo. Ações coletivas: enfoque sobre a legitimidade ativa. São Paulo: Liv. e Ed. Universitária de Direito, 2004.

SANTOS, Boaventura Sousa. Crítica da Razão Indolente: contra o desperdício da experiência. 2. ed. Porto: Afrontamento, 2002.

Recebido em: 03 de abril de 2017 Aceito em: 01 de novembro de 2017 